\title{
MIGRAÇÃO E CRIME: A LEI 6.815, DE 1980
}

Marcia Anita Sprande/ ${ }^{1}$

O artigo analisa o debate e as circunstâncias do envio ao Congresso Nacional, em 1980, do projeto de lei que seria sancionado como Lei 6.815, de 1980 (Estatuto do Estrangeiro). Num contexto de ditadura militar, em plena vigência da Guerra Fria, da Operação Condor e da Lei de Segurança Nacional, o texto enviado pelo General João Batista Figueiredo é intensamente criticado por parlamentares de oposição, intelectuais, sindicatos e pela grande imprensa. Além de apresentar os principais elementos que pautaram o debate parlamentar e os aspectos mais questionados da proposta de lei, o artigo analisa teoricamente a visão do estrangeiro como ameaça, numa tradição legislativa que remonta ao Império mas que, no período analisado, tem características próprias ligadas aos conceitos de guerra interna e de subversão. Busca apresentar subsídios para legisladores e especialistas no tema e permitir ao leitor refletir sobre a resiliência possível deste discurso (de trinta e cinco anos atrás) nos debates contemporâneos.

Palavras-chave: Estatuto do Estrangeiro, antropologia da política, Congresso Nacional, criminalização das migrações, segurança nacional.

Para Paulinho Gal Dull, in memoriam.

Art. 2o $\mathrm{Na}$ aplicação desta Lei atender-se-á precipuamente à segurança nacional (...).

Art. 3ำ A concessão do visto, a sua prorrogação ou transformação ficarão sempre condicionadas aos interesses nacionais.

(Lei no 6.815, de 19 de agosto de 1980 - Estatuto do Estrangeiro)

1 Antropóloga, integrante do Comitê de Migrações e Deslocamentos da Associação Brasileira de Antropologia. Assessora técnica do Senado Federal. Brasília, DF, Brasil. 
Como os demais textos legais, as leis migratórias também são marcadas por circunstâncias e subjetividades. Um dos argumentos mais fortes para revogação da Lei 6.815, de 19 de agosto de 1980, o Estatuto do Estrangeiro, é o fato de ter sido elaborada, votada e sancionada em um período de exceção - a ditadura militar - no qual predominava a ideologia da segurança nacional, sendo o estrangeiro visto como potencial criminoso. O presente artigo procura mostrar como esta ideologia foi incorporada ao texto legal, a que estrangeiros temia e qual o momento político que atravessava o país.

Diante da tramitação e discussão de uma nova Lei de Migrações no Congresso Nacional (Projeto de Lei $n^{\circ} 2516$, de 2015²), o artigo traz subsídios importantes para legisladores e para a sociedade civil interessada no tema. Além disso, permite ao leitor refletir sobre a resiliência deste discurso de trinta e cinco anos atrás que, por sua vez, segue a tradição de leis migratórias extremamente seletivas, racistas e conservadoras.

\section{Breve introdução teórico-legislativa}

O pensador alemão Georg Simmel, em texto escrito em 1908, coloca o estrangeiro estruturalmente na mesma categoria dos indigentes e dos "inimigos internos". Por quê? Segundo ele, porque, como os indigentes e os inimigos internos, os estrangeiros seriam um elemento do próprio grupo, que "se de um lado, são imanentes e têm uma posição de membros, por outro lado estão fora dele e o confrontam" ${ }^{\prime 3}$.

Simmel também pondera sobre a objetividade e a liberdade como características intrínsecas ao estrangeiro, decorrente de sua condição de pessoa "de fora". Em função disso, o estrangeiro não estaria "amarrado a nenhum compromisso que poderia prejudicar sua percepção, entendimento e avaliação do que é dado" ${ }^{\prime 4}$. Tal liberdade, no entanto, conteria possibilidades avaliadas como perigosas pelo grupo: "nas insurreições de todos os tipos, a facção atacada tem reivindicado, desde o começo dos tempos, que a provocação veio de fora, por meio de emissários e instigadores" ${ }^{\prime}$.

Em prefácio à obra "A Imigração ou o Paradoxo da Alteridade", de Abdelmalek Sayad, o sociólogo francês Pierre Bourdieu, em trecho já bastante conhecido, afirma que "o imigrante é atopos, sem lugar, deslocado, inclassificável"6. Sayad, no entanto, pensa na possibilidade de um lugar para o estrangeiro, embora este seja

\footnotetext{
2 Sua tramitação iniciou-se no Senado, como Projeto de Lei do Senado no 288, de 2013, do Senador Aloysio Nunes Ferreira (PSDB-SP). Para examiná-lo na Câmara dos Deputados, foi criada Comissão Especial, presidida por Bruna Furlan (PSDB-SP) e tendo como relator Orlando Silva (PCdoB-SP). 
um lugar perigoso, pois fora da ordem jurídica e política nacional. Por ocupar este lugar fora da ordem, o estrangeiro seria sempre uma ameaça:

Uma ameaça tanto maior (i.e., mais subversiva) quanto provém do exterior (da alteridade, da estranheza, da alogeneidade, da exterioridade, coisas que as categorias constitutivas da ordem social não podem integrar e interpretar segundo sua lógica própria, a lógica ou o gênio do "nacional")7.

Mais do que isso, a participação política não lhe seria permitida justamente por ocupar este lugar fora da identidade e da homogeneidade:

O imigrante "põe em "risco" a ordem nacional forçando a pensar o que é impensável, a pensar o que não deve ser pensado ou o que não deve ser pensado para poder existir; forçando-a a revelar seu caráter arbitrário (...), a desmascarar seus pressupostos; forçando-a a revelar a verdade de sua instituição e a expor suas regras de funcionamento ${ }^{8}$.

No caso da legislação produzida no período da ditadura militar e num contexto de Guerra Fria ${ }^{9}$, há diferenciais teóricos importantes em relação a essa literatura: a ameaça que vem de fora ${ }^{10}$ é pensada como intrinsecamente ligada aos "inimigos internos", os brasileiros considerados "subversivos"11.

Ou seja, ao estrangeiro "alienígena" equivaleria, estruturalmente, tanto em termos de suspeição política quanto de necessidade de controle jurídico, o cidadão brasileiro "subversivo". Além de ocuparem uma mesma posição estrutural, estes dois grupos, na medida em que poderiam entrar potencialmente em relação, eram vistos como extremamente ameaçadores para o regime e para a "segurança nacional". Mas de que "segurança nacional" estamos falando?

Para entender o conceito de "segurança nacional" instrumentalizado pelos militares, é preciso ler os quatro primeiros artigos do Decreto-Lei ${ }^{12} n^{0} 314$, de 13 de março de 1967 ("Lei de Segurança Nacional"), que "define os crimes contra a segurança nacional, a ordem política e social e dá outras providencias".

Art. 1o Toda pessoa natural ou jurídica é responsável pela segurança nacional, nos limites definidos em lei.

Art. 20 A segurança nacional é a garantia da consecução dos objetivos nacionais contra antagonismos, tanto internos como externos.

7 Ibidem, p. 273.

8 Ibidem, p. 274.

9 Assim denominado o período histórico entre o final da Segunda Guerra Mundial (1945) e a extinção da União Soviética (1991), marcado por disputas estratégicas e conflitos indiretos entre os Estados Unidos e a União Soviética, pela hegemonia política, econômica e militar no mundo.

${ }^{10}$ Eque tinha sua concretude em um grupo específico de estrangeiros, aqueles considerados politicamente revolucionários, alinhados à União Soviética ou Cuba, e/ou exilados das ditaduras vizinhas.

${ }^{11}$ Do latim subvertere, revolver de baixo para cima; arruinar, derribar, desordenar, perturbar, transtornar.

${ }^{12}$ Decreto com força de lei (ou seja, entra imediatamente em vigor). Deixaram de existir com a Constituição de 1988. 
Art. 3ํㅗ A segurança nacional compreende, essencialmente, medidas destinadas à preservação da segurança externa e interna, inclusive a prevenção e repressão da guerra psicológica adversa e da guerra revolucionária ou subversiva.

§ 1 o A segurança interna, integrada na segurança nacional, diz respeito às ameaças ou pressões antagônicas, de qualquer origem, forma ou natureza, que se manifestem ou produzam efeito no âmbito interno do país.

$\S 2$ o A guerra psicológica adversa é o emprego da propaganda, da contrapropaganda e de ações nos campos político, econômico, psicossocial e militar, com a finalidade de influenciar ou provocar opiniões, emoções, atitudes e comportamentos de grupos estrangeiros, inimigos, neutros ou amigos, contra a consecução dos objetivos nacionais.

$\S 3$ o A guerra revolucionária é o conflito interno, geralmente inspirado em uma ideologia ou auxiliado do exterior, que visa à conquista subversiva do poder pelo controle progressivo da Nação.

Art. 4ㅇNa aplicação deste decreto-lei o juiz, ou Tribunal, deverá inspirar-se nos conceitos básicos da segurança nacional definidos nos artigos anteriores. (grifos meus)

\section{Em todo o Decreto-Lei, a palavra estrangeiro(a) aparece outras 13 (treze)} vezes, todas no Capítulo II - Dos crimes e das penas ${ }^{13}$. Além disso, o artigo $8^{\text {o }}$

\footnotetext{
${ }^{13}$ Artigo 5o - Tentar, com ou sem auxílio estrangeiro, submeter o território nacional, ou parte dele, ao domínio ou soberania de outro país, ou suprimir ou pôr em perigo a independência do Brasil: reclusão, de 5 a 20 anos; Artigo 6o - Entrar em entendimento ou negociação com governo estrangeiro ou seus agentes, a fim de provocar guerra ou atos de hostilidade contra o Brasil: reclusão, de 5 a 15 anos; Artigo 7으 - Praticar atos de hostilidade contra potência estrangeira, capazes de provocar, por parte desta, guerra ou represálias contra o Brasil: reclusão, de 3 a 10 anos; Artigo 11 - Redistribuir material ou fundos de propaganda de proveniência estrangeira, sob qualquer forma ou a qualquer título, para a infiltração de doutrinas ou ideias incompatíveis com a Constituição: reclusão, de 1 a 5 anos. Parágrafo único. Se a propaganda de que trata o artigo, utilizando o material ou fundos de proveniência estrangeira, é feita a fim de submeter o Brasil a outro país: reclusão, de 2 a 8 anos; Artigo 12 - Formar ou manter associação de qualquer título, comitê, entidade de classe ou agrupamento que, sob a orientação ou com o auxílio de governo estrangeiro ou organização internacional, exerça atividades prejudiciais ou perigosas à segurança nacional: reclusão, de 1 a 5 anos; Art. 13 - Promover ou manter, em território nacional, serviço de espionagem em proveito de país estrangeiro ou de organização subversiva: reclusão, de 2 a 10 anos. $\S 2^{\circ}$ - Destruir, falsificar, subtrair, fornecer ou comunicar a potência estrangeira, organização subversiva ou a seus agentes ou, em geral, a pessoa não autorizada, documentos, planos ou instruções classificados como sigilosos por interessarem à segurança nacional: reclusão, de 3 a 10 anos; § 3으 - Entrar em relação com governo estrangeiro, organização subversiva ou seus agentes, para o fim de comunicar qualquer outro segredo concernente à segurança nacional: reclusão, de 1 a 5 anos; Art. 19 - Ofender publicamente, por palavras ou escrito, chefe de governo de nação estrangeira: detenção, de 6 meses a 2 anos; Art. 20 - Exercer violência de qualquer natureza, contra Chefe de Governo estrangeiro, quando em visita ao Brasil ou de passagem pelo seu território: reclusão, de 1 a 2 anos, além da correspondente à violência; Art. 28 - Matar, por motivos de facciosismo ou inconformismo político-social, quem exerça autoridade pública, ou estrangeiro que se encontre no Brasil, a convite do Governo brasileiro, a serviço de seu País ou em missão de estudo: reclusão, de 12 a 30 anos; Art. 43. São circunstâncias agravantes, quando não elementares do crime: (...) II - ter sido o crime praticado com a ajuda de qualquer espécie ou sob qualquer título, prestada por Estado ou organização internacional ou estrangeira.
} 
penaliza com reclusão de 3 a 10 anos quem "aliciar indivíduos de outra nação para que invadam o território brasileiro, seja qual for o motivo ou pretexto".

Dentro de tal lógica (antagonismo interno, conflito interno e segurança interna), a estrangeirização - nos termos de Simmel, Bourdieu e Sayad - do nacional considerado subversivo levará a edição de dois Atos Institucionais ${ }^{14}$, ambos do dia 05 de setembro de 1969. O Al -13 institui a pena de banimento para o brasileiro que "se tornar inconveniente, nocivo ou perigoso à segurança nacional" e o Al -14 altera o § 11 do art. 150 da Constituição de 1967 para permitir a "pena de morte, de prisão de perpétua, de banimento, ou confisco, nos casos de guerra externa psicológica adversa, ou revolucionária ou subversiva".

Ao defender que era preciso impedir de ingressar no país, prender, deportar ou expulsar estrangeiros em nome da segurança nacional, a ditadura militar aprofunda uma percepção da periculosidade do estrangeiro já presente na legislação migratória e de colonização desde o século XIX, como mostram os trabalhos de Giralda Seyferth, antropóloga do Museu Nacional (UFRJ). Analisando a trajetória das categorias imigrantes, estrangeiros, colonos e alienígenas, a pesquisadora mostra como referida legislação sempre dialogou com a criminalização (e com a eugenia), num cenário marcado pelo nacionalismo e sua intolerância para com a diferença cultural ou étnica.

Analisando as memórias do Visconde de Abrantes, que fora à Prússia com a missão diplomática de atrair emigrantes alemães, Seyferth identifica qual era o perfil do "colono ideal": sóbrio, resignado, trabalhador e respeitador das autoridades. Abrantes, em sua missão, também buscava informações policiais, com o intuito de evitar "vagabundos" ou "imorigeros"15, como são chamadas as "pessoas que não sabem se comportar, não apresentam boas maneiras, são devassas ou libertinas"16.

O trabalho de Giralda Seyferth identifica no engajamento político, somado à mobilidade espacial, outro tipo de potencial periculosidade do estrangeiro, que seria retomada com força na lei de 1980:

As situações conflituosas, o aparente desafio às leis e autoridades (...) a mobilidade espacial (...) deixaram à mostra um colono indesejado, politizado - estrangeiro, problemático, desqualificado como "comunista"17.

\footnotetext{
${ }_{14}$ Os Atos Institucionais foram normas e decretos elaborados no período de 1964 a 1969, durante o regime militar no Brasil. Neste período foram decretados 17 atos institucionais regulamentados por 104 atos complementares. Foram editados pelos Comandantes-em-Chefe do Exército, da Marinha e da Aeronáutica ou pelo Presidente da República, com o respaldo do Conselho de Segurança Nacional. Tais normas estavam acima de todas as outras, inclusive (ou sobretudo) da Constituição.

${ }^{15}$ ABRANTES apud SEYFERTH, Giralda. Imigrantes, estrangeiros: a trajetória de uma categoria incomoda no campo político, p. 06.

${ }^{16}$ Dicionário Michaelis.

17 SEYFERTH, op. cit., p. 8.
} 
Importante registrar, até pela constante reatualização do tema, que enquanto as restrições aos europeus eram referidas a questões como profissão, moralidade, idade e estado de saúde, no caso dos asiáticos e africanos entrava com força a questão racial. O Decreto 528, de 28 de junho de 1890, por exemplo, "tornou livre a entrada de indivíduos válidos e aptos e não sujeitos à ação criminal no seu país, excetuando os nativos da Ásia e da África, os mendigos e os indigentes"18. Sobretudo aos chineses cabia a peja de "representantes de uma civilização decadente, obscurecida pelo ópio"19.

Em sua análise, Seyferth vai mostrar que normas de 1907 e 1911 também impediam o ingresso de maiores de 60 anos, de doentes, de quem exercesse profissão ilícita, de criminosos, desordeiros, mendigos, vagabundos, dementes ou inválidos e que, a partir de 1921, a legislação passa a prever a expulsão de indesejáveis, principalmente se banidos ou expulsos de outro país.

Ou seja, a suspeição contra o estrangeiro faz parte de toda formulação legislativa dos últimos anos do Império e da Republica, dificultando o ingresso de "indesejáveis" ou facilitando sua expulsão. A classificação em indesejáveis incluía quesitos como raça, cor, origem, faixa etária e estado de saúde, como também subjetividades ligadas à moralidade, à aptidão ao trabalho e à segurança nacional".

Outra forma de perceber este filtro do desejo está no imenso temor à mobilidade, que se evidencia no Decreto Lei 406, de maio de 1938, que "dispõe sobre a entrada de estrangeiros no território nacional", e que incluiria na lista de indesejáveis os "ciganos e congêneres" e os que "se entreguem à prostituição ${ }^{20}$. Ainda no Estado Novo (1938-1945), o Decreto Lei 7967, de 1945, que "dispõe sobre a imigração e a colonização", determina em seu artigo $2^{\text {o }}$ que será atendida, na admissão dos imigrantes, "a necessidade de preservar e desenvolver, na composição étnica da população, as características mais convenientes da sua ascendência europeia, assim como a defesa do trabalhador nacional". Entre os

\footnotetext{
18 Ibidem, p. 11.

${ }^{19}$ Ibidem. Chama a atenção que no caso de asiáticos e africanos, sua entrada no país dependeria de autorização do Congresso Nacional.

${ }^{20}$ Ibidem, p. 14. O Decreto Lei 406, de 04 de maio de 1938, já em seu artigo primeiro lista que estrangeiros são impedidos de entrar no país: os aleijados ou mutilados, inválidos, cegos, surdos-mudos; os indigentes, vagabundos, ciganos e congêneres; os doentes de moléstias infectocontagiosas graves, especialmente tuberculose, tracoma, infecção venérea, lepra e outras referidas nos regulamentos de saúde pública; os que apresentem lesões orgânicas com insuficiência funcional; os menores de 18 anos e maiores de 60, que viajarem sós, salvo as exceções previstas no regulamento; os que não provem o exercício de profissão lícita ou a posse de bens suficientes para manter-se e às pessoas que os acompanhem na sua dependência; os de conduta manifestamente nociva à ordem pública, à segurança nacional ou à estrutura das instituições; os já anteriormente expulsos do país, salvo se o ato de expulsão tiver sido revogado; os condenados em outro país por crime de natureza que determine sua extradição, segundo a lei brasileira; e os que se entreguem à prostituição ou a explorem, ou tenham costumes manifestamente imorais.
} 
indesejáveis, os mesmos "indigentes ou vagabundos", "nocivos à ordem pública, à segurança nacional ou à estrutura das instituições".

Ambos os decretos só seriam revogados pela Lei 6.815, de 1980. A mesma lei revogaria uma exceção à regra, a progressista Lei 2526, de 05 de julho de 1955, que isentava de visto consular os turistas cidadãos de países americanos.

No entanto, a Lei 6.815 não foi a primeira norma migratória produzida pelos militares que tomaram o poder em 1964. Em novembro daquele ano, o General Castelo Branco sancionou a Lei $n^{\circ} 4473$, que dispõe sobre as atribuições das autoridades para fiscalizar a entrada de estrangeiros no território nacional e determina, em seu artigo primeiro, que estas atribuições, incluindo o impedimento, ficarão a cargo das "autoridades de Polícia".

Editado em janeiro de 1969, o Decreto Lei no 417 dispõe sobre a expulsão de estrangeiro, por decreto do Presidente da República, sempre que este atente contra a segurança nacional, a ordem política ou social, a tranquilidade e moralidade públicas e a economia popular, ou cujo procedimento o torne nocivo ou perigoso a conveniência ou aos interesses nacionais. $\mathrm{O}$ decreto permite que a expulsão se dê mediante investigação sumária, no prazo de quarenta e oito horas. No entanto, havia garantias de que não seria expulso estrangeiro que tivesse cônjuge ou filho brasileiro, dependente de economia paterna.

Nove meses depois, foi editado o Decreto-Lei no 941, de 13 de outubro de 1969, que "define a situação jurídica do estrangeiro e dá outras providências". Parte considerável de seu texto foi utilizada para a redação do Projeto de Lei $n^{\circ}$ 09, de $1980^{21}$ e, consequentemente, da Lei $6.815^{22}$.

Assim, o art. 5o do Decreto-Lei $n^{\circ} 941$ determina que não se concederá visto ao estrangeiro "nocivo à ordem pública". Na versão de 1980, será acrescida a expressão "ou aos interesses nacionais". Já seu artigo 73, que incorpora o D-L 417 ao determinar que será passível de expulsão o estrangeiro que, por qualquer forma, atentar contra a segurança nacional, a ordem política ou social, a tranquilidade ou a moralidade pública e a economia popular, ou cujo procedimento o torne nocivo ou perigoso à conveniência e aos interesses nacionais, permanece inalterado na Lei 6.815. O artigo 74 do Decreto-Lei 941, que determina que não poderá ser expulso do país o estrangeiro que tiver cônjuge ou filho brasileiro, não aparece na primeira versão da Lei 6.815, o que levará à inúmeros protestos, como veremos a seguir.

\footnotetext{
${ }^{21}$ Vale a pena registrar que, enquanto no Decreto-Lei no 941 a expressão "segurança nacional" aparece três vezes, na Lei 6.815, de 1980, ela é utilizada catorze vezes.

22 Isto levaria a questionamentos do Relator da Comissão Mista criada para examinar o PL 09/1980, uma vez que a oposição estaria criticando artigos que já estavam em vigor pelo DL941. Ao que os oposicionistas respondiam que, por ter sido um Decreto Lei, não havia sido votado pelo Congresso Nacional e, portanto, sido objeto de debates.
} 
Finalmente, é o Decreto-Lei no 941, de 1969 quem vai determinar que caberá à Polícia Federal o controle, registro, prorrogação de prazo de estada, expedição de documento de identidade, expulsão e naturalização de estrangeiro, além de prover orçamento específico para que o órgão possa gerenciar as migrações.

\section{Lei 6.815, de 1980 (Estatuto do Estrangeiro): o debate e a conjuntura}

Este projeto tem cheiro de sangue. (Paulo Brossard. Diário do Congresso Nacional, 06/08/1980).

Por que o projeto agora nesta altura da vida brasileira? Qual o tumulto que está existindo? Qual o problema criado pelos estrangeiros que chegam ao Brasil? (Jorge Uequed, Diário do Congresso Nacional, 05/08/1980).

A partir de pesquisa realizada no banco de dados "Discursos e Notas Taquigráficas" 23 da Câmara dos Deputados, utilizando a variável "estrangeiros", no período de 01 de janeiro a 31 de dezembro de 1980, foram encontrados 269 (duzentos e sessenta e nove) discursos no Plenário. Destes, 140 (cento e quarenta) referem-se ao envio ao Congresso, pelo Executivo, de proposta de nova lei de estrangeiros, que tramitou como Projeto de Lei $n^{\circ}$ 9/80-CN, e os percalços de sua aprovação. Para o ano de 1981, o exercício foi com a variável "Estatuto dos Estrangeiros", tendo sido identificados 25 (vinte e cinco) documentos referentes à mudança enviada ao Congresso pelo governo, em resposta às críticas sofridas pela lei aprovada em agosto de 1980.

No primeiro período analisado (ano de 1980), chama a atenção o grande número de discursos denunciando interesses "alienígenas" na Amazônia, ameaçando nossa soberania e nossos minérios. Neste pacote se destacam as críticas de políticos aliados ao governo militar à presença de religiosos estrangeiros, que estariam "insuflando" populações tradicionais a lutarem por seus direitos, pondo em risco a segurança nacional:

(...). Os interesses pessoais e, já agora, internacionais, acionados por brasileiros de pouca ou nenhuma coragem cívica, acompanhados de organizações religiosas comandadas pelos novos corifeus, importados do exterior, põem até em risco a segurança Nacional. (...) Estes homens, representantes da Igreja Católica, se lançam em campanhas perigosas para a Nação brasileira, como no caso da demarcação das terras indígenas no Amajari. (...). Por uma coincidência terrível, os padres e bispos envolvidos nesses episódios são sempre estrangeiros, como já disse eu em outra ocasião, sem nenhum compromisso com este País. Algo de muito importante existe comandando essas ações constantes e desagregadoras, em detrimento da unidade nacional ${ }^{24}$.

\footnotetext{
${ }^{23} \mathrm{Cf}$. < http://www2.camara.leg.br/deputados/discursos-e-notas-taquigraficas >.

${ }^{24}$ Discurso do Dep. Hélio Campos (PDS - RR). Diário do Congresso Nacional (DCN), 25/10/1980, p. 13111-13112.
} 
De parte da oposição à ditadura, são inúmeros os discursos contra o favorecimento do governo a grupos econômicos estrangeiros (bancos, mineradoras, indústria química, indústria farmacêutica, do setor de produção de cana e álcool, da agricultura), denominados multinacionais e a aquisição de terras por estrangeiros, especialmente na Amazônia.

Vale lembrar que estávamos no décimo-sexto ano de ditadura militar e que também nos países vizinhos militares haviam tomado o poder: Argentina, Bolívia, Chile, Paraguai e Uruguai. Em 1975, sob o comando do General chileno Augusto Pinochet, havia sido formalizado a Operação Condor, que consistia no apoio político-militar entre os governos da região, visando perseguir os que se opunham aos regimes autoritários. De uma fase inicial, de troca de informações entre os países-membros, a operação evoluiu para "trocas" e execuções de opositores nos territórios dos países que formavam a aliança e, finalmente, pela perseguição e assassinato de inimigos políticos no exterior.

Em novembro de 1978, um comando do Exército uruguaio, com a conivência do regime militar brasileiro, sequestrara em Porto Alegre (RS) um casal de militantes da oposição uruguaia, Universindo Rodríguez Díaz e Lílian Celiberti e seus dois filhos, Camilo (8 anos) e Francesca (3 anos). O caso, flagrado por jornalistas, causara comoção.

Em 1980, o General Figueiredo havia visitado o General Alfredo Stroessner, no Paraguai, em abril, e o General Jorge Videla, na Argentina, em maio. O envio da Mensagem 64, de 1980, com o texto do que viria a ser o Estatuto do Estrangeiro, acontece no retorno destas viagens, o que seria percebido pelos parlamentares de oposição como um de seus resultados mais evidentes: facilitar a expulsão de estrangeiros considerados inimigos do regime.
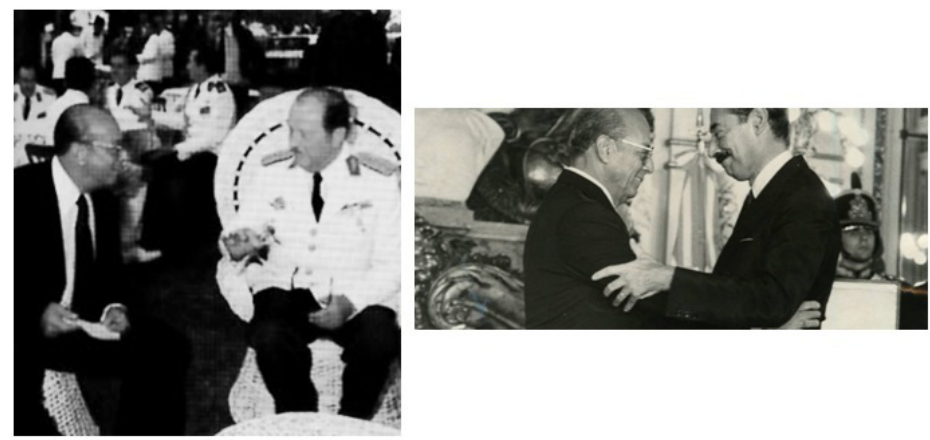

Figura 1: visita do General Figueiredo ao Paraguai e a Argentina, em abril e maio de 1980, respectivamente. Na foto da esquerda, um registro do seu encontro com o General Stroessner. Na direita, com o General Videla.

O fato da Mensagem ter sido enviada ao Congresso em caráter de urgência é questionado pela oposição e, posteriormente, pela imprensa. Isto porque, por força de Emenda Constitucional n. 1, de 1969, se o Presidente da República 
julgasse urgente um projeto, poderia solicitar que a sua apreciação fosse feita em sessão conjunta do Congresso Nacional, dentro do prazo de quarenta dias. $\mathrm{Na}$ falta de deliberação dentro deste prazo, o projeto seria considerado aprovado por decurso de prazo $^{25}$. Foi, como veremos a seguir, o que aconteceu com o Projeto de Lei $n^{\circ}$ 9/80-CN após o relator rejeitar 32 (trinta e duas) das 34 (trinta e quatro) emendas apresentadas pela oposição.

A Comissão Mista criada para examinar a matéria, formada por Deputados e Senadores, teve como relator o Senador Bernardino Viana ( $\mathrm{PDS}^{26}-\mathrm{PI}$ ) e como presidente o Deputado Marcelo Cerqueira (PMDB-RJ). O primeiro registro sobre o Projeto de Lei no 9/80-CN no banco de dados de discursos da Câmara dos Deputados se dá em 04 de junho de 1980, quando presidente da Comissão Mista enfatiza aspectos do texto que considera inconstitucionais e obscurantistas:

A pretexto de "reduzir o afluxo de estrangeiros", que deveria ser o estabelecimento de uma nova política imigratória, o projeto na verdade encerra uma hostilidade tenaz ao estrangeiro ora residente em nosso pais, irregularmente ou não. Não enxergam os autores desse infeliz projeto que, para agradar e servir os ditadores do Cone Sul, na prática estão cerceando o turismo e o comércio exterior, dificultando o intercâmbio entre brasileiros e os demais povos e impedindo, na prática, a entrada de cientistas e professores de outras nacionalidades.

A proposta em tudo estabelece restrições ao ingresso ou à visita de estrangeiros e coloca, acima de todas as restrições, as que forem ditadas pelos "interesses nacionais". O projeto não define o que sejam "interesses nacionais". Assim, mesmo que alguém tenha satisfeito todas as condições para permanecer ou vir ao Brasil, atendido a todas as exigências da lei e do seu regulamento, poderá ser impedido de aqui ficar em nome dos "interesses nacionais" - norma nitidamente autoritária. Interesses nacionais eram o que a vontade do Duce ou do Führer estabelecesse. Agora e aqui quem definirá os "interesses nacionais"? O Delegado de Polícia de Jaguarão, de Foz do Iguaçu ou de Dionísio Cerqueira? Ou os investigadores da polícia marítima nos aeroportos? Tudo está, entretanto, muito claro. Trata-se de uma lei destinada a dar carta branca à Polícia Federal para devolver aos respectivos ditadores os que pretenderem escapar às gestapos locais, em nossas fronteiras ${ }^{27}$.

Da leitura dos discursos constantes do banco de dados da Câmara dos Deputados, pode-se identificar quais foram as principais críticas da oposição ao Projeto de Lei $n^{\circ}$ 9/80-CN:

1) Artigos $1^{\circ}, 2^{\circ}, 3^{\circ}$ e $7^{\circ}$ - por resguardar aos "interesses nacionais" o ingresso, permanência e saída de estrangeiro do Brasil; por determinar que a

\footnotetext{
${ }^{25}$ Agradeço a Thales Chagas Machado Coelho pela importante informação.

${ }^{26}$ O Partido Democrático Social (PDS) foi um partido político brasileiro de direita, apoiador da ditadura militar. Desdobramento da Arena, foi fundado em 30 de janeiro de 1980, após o fim do sistema bipartidário criado pelo Regime Militar de 1964.

27 Discurso de Marcelo Cerqueira (PMDB-RJ). DCN, 04/06/ 1980, p. 5140-5141.
} 
aplicação da lei atenderá à segurança nacional, que também condicionará a concessão do visto, a sua prorrogação ou transformação; e que não se concederá visto ao estrangeiro considerado nocivo à ordem pública ou aos interesses nacionais ${ }^{28}$, velha restrição, como já vimos, mas que neste contexto assume cores mais sombrias. A crítica à ideologia da segurança nacional vai aparecer em inúmeros pronunciamentos:

Expressão vaga, que só pode ser definida pelo arbítrio ${ }^{29}$.

Voltamos ao caráter ditatorial, violento, absurdo dessa Lei, que logo no artigo $2 \underline{0}$ consagra o culto, a idolatria a essa estranha doutrina de segurança nacional, imposta ao Brasil e às demais nações latino-americanas nos laboratórios de West Point ${ }^{30}$.

O que o Conselho de Segurança Nacional tem a ver com o projeto dos estrangeiros? Quais são as razões, quais os urdimentos desse projeto (...)?31

Aí está a ideologia da segurança nacional, que enquadra qualquer brasileiro, nativo ou não, desde que use reivindicar ou protestar contra o esbulho de sua cidadania, garantida pela Declaração de Direitos Humanos ${ }^{32}$.

O que é isto? Quem julga ou interpreta o interesse nacional? ?3 $^{33}$

Qual a lei, qual o regulamento que define este "procedimento nocivo à conveniência e aos interesses nacionais"? Este projeto não o faz e nem diz qual será. Portanto ficará ao arbítrio da autoridade administrativa $(. . .)^{34}$.

Tudo se insere no quadro obsessivo da Segurança Nacional, agora em processo evolutivo de segurança continental. É o obscurantismo que se espaIha (...). Este Estatuto dos Estrangeiros é um novo Al-5 (...) especialmente para os exilados políticos (...) e missionários da Igreja ${ }^{35}$.

2) Artigos 18, 74 e 101 - por determinarem que a concessão do visto permanente poderá ficar condicionada ao exercício de atividade certa e à fixação em região determinada do território nacional; que o Ministro da Justiça poderá modificar as normas de conduta impostas ao estrangeiro e designar outro lugar para sua residência; que o estrangeiro admitido para desempenho de atividade

\footnotetext{
${ }^{28}$ Na legislação migratória então em vigor, o $D L$ 941, de 1969, o art. 10 determinava apenas: "Todo estrangeiro poderá entrar no Brasil desde que satisfaça as necessidades estabelecidas neste

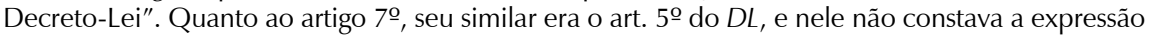
"e aos interesses nacionais".

${ }^{29}$ Discurso de Marcelo Cerqueira (PMDB-RJ). DCN, 05/08/1980, p. 6909.

30 Discurso de Walter Silva (PMDB-RJ). DCN, 02/08/1980, p. 6795.

${ }^{31}$ Discurso de Airton Soares (PT-SP). DCN, 0/08/1980, p. 6913.

32 Discurso de Benedito Marcílio (PT-SP). DCN, 06/08/1980, p. 1733.

${ }^{33}$ Questionamento de Jorge Uequed (PMDB-RS). Resposta do governista Odacir Soares (PDS-RO): "O interesse nacional é matéria da jurisprudência dos nossos tribunais. É matéria pacífica hoje". DCN, 06/08/1980, p. 1735.

${ }^{34}$ Discurso de Brabo de Carvalho (PMDB-PA). DCN, 06/08/1980, p. 1738.

35 Discurso de Marcos Freire (PMDB-PE). DCN, 06/08/1980, p. 1743.
} 
profissional certa, fixado em região determinada, não poderá mudar de domicílio nem de atividade profissional ou exercê-la fora daquela região $0^{36}$.

Estabelece o confinamento de estrangeiros no território nacional. (...). Tem esse artigo o sentido claro de confinar (...) os missionários, sejam eles padres católicos ou missionários protestantes que, a critério do governo, possam incomodar, na sua pregação evangélica, os detentores do poder $(\ldots)^{37}$.

Esta fixação do estrangeiro (...) é, indiscutivelmente, a formação de um gueto, de um verdadeiro confinamento do estrangeiro ${ }^{38}$.

3) Artigo 26 - por determinar que o visto concedido pela autoridade consular configura mera expectativa de direito, podendo a entrada, a estada ou o registro do estrangeiro ser obstado ocorrendo qualquer dos casos do artigo $7 \stackrel{0}{ }$, ou a inconveniência de sua presença no território nacional, a critério do Ministério da Justiça. A maior crítica se referia ao $\S 2$ o do art. 26 , por determinar que o impedimento de qualquer dos integrantes da família poderia estender-se a todo o grupo familiar ${ }^{39}$.

Quem tem o mais elementar conhecimento de Direito Penal sabe que a pena não pode passar da pessoa do criminoso. (...) Com este dispositivo recuamos à pré-história do Direito Penal no mundo, ao admitir-se que o governo brasileiro possa penalizar a família do estrangeiro que porventura ele queira impedir de entrar no país e expulsá-lo juntamente com seus familiares. ${ }^{40}$

Clara violação do § 13 do art. 153 da Constituição, o que levou Dom Luciano Mendes a chamá-lo de "pena infamante"

4) Artigos 28 e 29 - por determinar que o estrangeiro admitido no território nacional na condição de asilado político ficará sujeito, além dos deveres que lhe forem impostos pelo Direito Internacional, a cumprir as disposições da legislação vigente e as que o Governo brasileiro lhe fixar e que o asilado não poderá sair do País sem prévia autorização do Governo brasileiro ${ }^{42}$.

\footnotetext{
${ }^{36}$ Não havia nenhuma previsão neste sentido na legislação migratória então em vigor, o $D L$ 941, de 1969.

${ }^{37}$ Discurso de Walter Silva (PMDB-RJ). DCN, 02/08/1980, p. 6796.

${ }^{38}$ Discurso de Carlos Sant' Anna (PP-BA). DCN, 06/08/1980, p. 1731.

${ }^{39}$ Na legislação migratória então em vigor, o DL 941, de 1969, o art. 38 tinha o mesmo teor deste art. 26, sem fazer referência, no entanto, ao Ministério da Justiça. Quanto ao parágrafo 20 do art. 26, no $D L$ ele corresponde ao $\S 2^{\circ}$ do art. 41, com o seguinte texto: "O impedimento do chefe de família estender-se-á a seus dependentes, mas o desembarque destes, no entanto, poderá ser autorizado desde que pessoa domiciliada no país, de comprovada idoneidade moral e financeira, assuma a responsabilidade por sua manutenção e eventual retirada do território brasileiro".

40 Ibidem.

${ }^{41}$ Discurso de Marcelo Cerqueira (PMDB - RJ). DCN, 05/08/1980, p. 6909.

${ }^{42}$ Na legislação migratória então em vigor, o DL 941, de 1969, o art. 28 corresponde ao art. 111, que finalizava apenas com a expressão "disposições deste decreto-lei". Quanto ao art. 29, corresponde ao art. 114 do $D L$, que afirma: "O estrangeiro admitido no Brasil como asilado não poderá dele sair sem prévia comunicação ao Governo brasileiro e obtenção do respectivo visto". O visto a que
} 
Em relação ao asilado, prevê o projeto no art. 28, que, além dos deveres que Ihe forem impostos pelo Direito Internacional e pelas disposições da legislação vigente, ficará sujeito "às que o Governo brasileiro lhe fixar" - não sem antes inaugurar no seu texto (art. 28) a versão terrivelmente reveladora do território brasileiro! ${ }^{43}$. irregular ${ }^{44}$.

5) Artigo 37 - por vedar a legalização da estada de clandestino e de

Permite a expulsão simples e sumária de tantos quantos estejam em caráter irregular $^{45}$.

6) Artigo 46 - por determinar que o estabelecimento hoteleiro, a empresa imobiliária, o proprietário, locador, sublocador ou locatário de imóvel e o síndico de edifício remeterão ao Ministério da Justiça os dados de identificação do estrangeiro admitido na condição de hóspede, locatário, sublocatário ou morador $^{46}$.

A consagração da delação (...). Visa tão só e simplesmente a seguir aqueles que forem destacados para sofrer-lhe a perseguição. Não é um artigo de lei para uma generalização, é um artigo de lei que visa exatamente a determinados grupos $(. . .)^{47}$.

7) Artigo 57 - referente à deportação, especialmente por seu parágrafo único, que determina que a deportação far-se-á para o país da nacionalidade ou de procedência do estrangeiro, ou para outro que consinta em recebê-lo ${ }^{48}$.

É uma barbaridade que rompe com as tradições do Direito brasileiro. ${ }^{49}$

8) Artigo 66 - por determinar que caberá exclusivamente ao Presidente da República resolver sobre a conveniência e a oportunidade da expulsão ou de sua revogação ${ }^{50}$.

se refere está no art. 69 do $D L:$ "O visto de saída a asilados políticos somente será concedido com expressa autorização do Ministro da Justiça". Este visto de saída para asilado desaparece da Lei 6.815.

${ }^{43}$ Discurso de Marcelo Cerqueira (PMDB - RJ). DCN, 05/06/ 1980, p. 5140-5141.

${ }^{44}$ Na legislação migratória então em vigor, o DL 941, de 1969, não havia nenhuma previsão neste sentido.

45 Discurso de Carlos Sant' Anna (PP-BA). DCN, 06/08/1980, p. 1731.

${ }^{46} \mathrm{Na}$ legislação migratória então em vigor, o $D L$ 941, de 1969, não havia nenhuma previsão neste sentido.

${ }^{47}$ Discurso de Walter Silva. DCN, 02/08/1980, p. 6797.

${ }^{48}$ Na legislação migratória então em vigor, o DL 941, de 1969, o art. 105 era muito semelhante: "A deportação far-se-á para o país de origem ou de procedência do estrangeiro, ou para outro que consinta em recebe-lo".

49 Discurso de Walter Silva. DCN, 02/08/1980, p. 6797.

${ }^{50}$ Mesmo texto do art. 66, mais seu parágrafo único, da legislação migratória então em vigor, o $D L$ 941, de 1969. 
9) Artigo 74 - por não mais incluir entre os impedimentos da expulsão o casamento com cônjuge brasileiro e/ou ter filho brasileiro ${ }^{51}$.

O malsinado projeto de lei está em rota de colisão com as generosas tradições do Brasil sobre a matéria desde a Constituição Imperial de 1824 (art. 6, no 4). (...) Até mesmo a Junta Militar, que, ao promulgar (sic) a Carta de 1969, retirou do texto constitucional a garantia da inexpulsabilidade do estrangeiro com cônjuge brasileiro ou filho brasileiro dependente da economia paterna, não ousou autorizar a expulsão, conservando expressamente a norma no Decreto-Lei no 941, de $1969^{52}$.

No dia 19 de junho de 1980, a Comissão Mista aprova o parecer do Relator, Senador Bernardino Viana (PDS-PI), que, como já foi dito, acata apenas duas das 34 emendas apresentadas pela oposição. A reação é imediata. O Dep. João Gilberto (PMDB-RS), vai à tribuna denunciar o que considera um estatuto autoritário:

O projeto de lei contraria a tradição jurídica do País, criando normas extraordinariamente severas para a permanência de estrangeiros e a conquista da cidadania brasileira por parte deles. (...) Está eivado por um espírito de perseguição a milhares de pessoas que hoje residem no Brasil, com uma situação jurídica não bem definida. Palestinos, coreanos, argentinos, uruguaios, chilenos e tantos outros passarão a ser expulsáveis se o Congresso aprovar como está o projeto. São mais de 300 mil estrangeiros em situação irregular. (...). Foram apresentadas 34 emendas por parlamentares de vários partidos. Somente duas, sem maior importância, foram aproveitadas pelo Sr. Relator. No resto, presidiu o parecer, o mesmo espírito exaltado do projeto original, desumano e antiético em relação aos perseguidos de outros países, aos banidos, aos apátridas e aos estrangeiros em geral. É preciso que se diga à comunidade brasileira, fruto ela própria da miscigenação e da imigração, descendente que somos a maioria do povo brasileiro - de imigrantes de diversas gerações, os nomes dos parlamentares que por causa da solidariedade irrestrita ao Governo que servem votaram pela rejeição de todas as emendas atenuantes da rigidez do projeto, ou garantidoras de situações concretas existentes aos milhares. São eles os Senadores Bernardino Viana, João Lúcio, Aloysio Chaves, Aderbal Jurema, Murilo Badaró e Raimundo Parente. E os Deputados Djalma Bessa, Osmar Leitão, Gomes da Silva, Osvaldo Melo e Hugo Napoleão. Estes parlamentares são desde ontem co-responsáveis por um projeto que desonra a tradição jurídica brasileira e o tratamento que historicamente dispensamos aos estrangeiros. (...) co-responsáveis por mais um ato de autoritarismo incrustrado na legislação ordinária brasileira, na tentativa de eternizar normas absolutistas e discriminatórias ${ }^{53}$.

\footnotetext{
${ }^{51}$ Na legislação migratória então em vigor, o DL 941, de 1969, o art. 74 garantia a inexpulsabilidade do estrangeiro que tivesse cônjuge brasileiro do qual não estivesse desquitado ou separado ou filho brasileiro dependente da economia paterna.

52 Discurso de Marcello Cerqueira. DCN, 04/06/1980.

${ }^{53}$ Discurso de João Gilberto (PMDB-RS). DCN. 21/06/1980, p. 6099.
} 
Neste ínterim, o governado "biônico" 54 do Paraná, General Ney Braga, alinhado ao governo desde o golpe de 1964, criticara publicamente o texto enviado ao Congresso, em defesa dos imigrantes que haviam colonizado aquele estado. $\mathrm{O}$ Deputado Álvaro Valle (PDS-RJ), também governista, busca tranquilizar a comunidade portuguesa, preocupada com as consequências da aprovação do projeto.

Em entrevista ao Jornal do Brasil, em 03 de junho de1980, narrada em pronunciamento de Marcelo Cerqueira (PMDB/RJ), um porta-voz do governo teria chegado a admitir que havia uma questão religiosa encerrada no projeto. Posteriormente, segundo o mesmo parlamentar, o governo anunciou uma campanha de amplo esclarecimento sobre sua iniciativa, veiculada no Jornal do Brasil de 15 de julho de 1980, que teria apenas aumentado a apreensão de todos:

Veja-se um exemplo: declarou-se que "uruguaios, argentinos e chilenos que buscam asilo no Brasil", se aqui estiverem clandestinamente, terão 90 dias para se regularizarem, "havendo acordo com seus países". Ora, é inimaginável um acordo com ditadores destes países para regularizar a situação dos opositores a que perseguem. (...) Ainda outro exemplo: fez-se referência à ameaça da imigração de dez milhões de asiáticos, em nova versão do "perigo amarelo" (...) criando dificuldades diplomáticas com todos os países da Ásia. (...). Foi nesse instante, infelizmente, que se recolheu do Ministro da Justiça justificativa que está realmente no nível do malsinado projeto. A inexpulsabilidade seria utilizada para "carimbar a permanência de marginais no ventre da mulher brasileira". Lamento ter que repetir esta frase, mas quero que fique nos Anais da Casa. Creio-a grosseira e vulgar, mas que o julgamento definitivo seja feito pelas mulheres brasileiras ${ }^{55}$.

Durante o recesso parlamentar de julho, nas palavras do Deputado Walter Silva (PMDB-RJ), acendeu-se, em todo o País, uma enorme discussão quanto ao "caráter arbitrário, fascista, desta lei (...) que possibilita a expulsão e deportação de refugiados e exilados políticos (...) o que significa devolvê-los à tortura e à morte" ${ }^{\prime \prime 56}$.

De fato, a reação firme da oposição ao projeto rapidamente foi incorporada por setores importantes da sociedade como a Conferência Nacional dos Bispos do Brasil (CNBB), Ordem dos Advogados do Brasil (OAB), Associação Brasileira de

${ }^{54}$ Cargos biônicos são aqueles cujos titulares foram investidos mediante a ausência de sufrágio universal e cujo parâmetro para escolha era a sanção das autoridades de Brasília à época do Regime Militar de 1964 nas décadas de 1960, 1970 e 1980. Tal centralismo garantiu a continuidade do regime e impediu que os objetivos traçados pelos militares fossem alvo de sedições políticas. $\mathrm{O}$ termo "biônico" foi popularizado no Brasil graças ao seriado O Homem de Seis Milhões de Dólares. A partir de 1966 surgiram os governadores biônicos, prefeitos biônicos em certas categorias de municípios e até senadores biônicos. No caso dos senadores o termo "biônicos" derivou também do Pacote de Abril de 1977 que alterou as regras para o pleito de 1978. Nele, cada estado escolheria um nome pela via indireta na renovação de dois terços das cadeiras mediante votação de um colégio eleitoral, o que deu à ARENA 21 das 22 cadeiras em jogo impedindo a repetição da rotunda vitória do MDB em 1974. Fonte: Wikipédia.

${ }_{55}$ Discurso de Marcelo Cerqueira (PMDB-RJ). DCN, 05/08/1980, p. 6908-6909.

56 Discurso de Walter Silva (PMDB-RJ). DCN, 02/08/1980, p. 6795. 
Imprensa (ABI), Sociedade Brasileira para o Progresso da Ciência (SBPC) e Anistia Internacional. O jornal "Le Monde" teria comentado o assunto. O próprio Papa João Paulo II, em visita ao país, demonstrara preocupação com o texto. Na terçafeira, dia 5 de agosto de 1980, o Movimento de Anistia e o Comitê Brasileiro de Solidariedade aos Povos da América Latina entregaram ao presidente da Câmara dos Deputados, Dep. Flávio Marcílio (PDS-PI), documento com mais de 17 mil assinaturas contra a Lei dos Estrangeiros. Entre os signatários estão expoentes da sociedade brasileira, como Jorge Amado, Celso Furtado, José Mindlin, Fernando Henrique Cardoso, Perseu Abramo, Apolônio de Carvalho, Jacob Gorender, Evaristo de Morais, Gianfrancesco Guarnieri, Francisco de Oliveira, Francis Hime, Ziraldo, Henfil, Hector Babenco, José Celso Correia, Suzana Amaral, Hélio Pelegrino, além de inúmeros representantes de entidades estudantis, sindicais, profissionais e parlamentares.

Diante de tantas críticas, o Líder do PDS na Câmara dos Deputados, Dep. Nelson Marchezan (PDS-RS), chegaria a ir à televisão para afirmar que o governo enviaria outro projeto para sanar as deficiências deste. Na tribuna, parlamentares governistas se alternam na defesa da matéria. De argumentos iniciais que justificavam o projeto pelo excesso de casamentos de conveniência, o governo passa a alegar que o projeto buscava impedir o ingresso de marginais e traficantes (sendo citado o caso de Ronald Biggs) ${ }^{57}$, terminando por se deter na defesa do "trabalhador nacional".

O Relator da matéria, Dep. Bernardino Viana (PDS-PI), ao defender a posição do governo, explicita que o aspecto mais criticado do projeto, a possibilidade de expulsão de estrangeiro casado com brasileira e/ou com filhos brasileiros, seria uma medida transitória para que se pudessem regularizar "os casamentos e os registros fraudulentos" ${ }^{\prime 58}$ que estariam sendo feitos no país. O assunto causou tanta polêmica que gerou uma nota à imprensa por parte do Itamaraty, que infelizmente não foi localizada para a elaboração deste artigo.

Finalmente, para defender a proposta de lei o relator recorre ao "interesse nacional", classificando os imigrantes fronteiriços como malfeitores:

Nós, que estamos no Governo (...) também defendemos os interesses nacionais e não vamos permitir que, neste País, como está acontecendo agora, entrem pelas fronteiras ocidentais, meridionais e setentrionais pessoas de todas as nacionalidades com o intuito de praticar o mal em nosso País, como se esta fosse uma terra de ninguém. (Muito bem!) ${ }^{59}$.

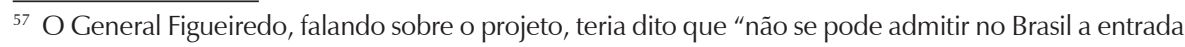
de toxicômanos". Ver Discurso de Otacílio Queiroz (PMDB-PB). DCN, 06/08/1980, p. 1728.

${ }^{58}$ Discurso de Bernardino Viana (PDS-PI). DCN, 27/06/1980, p. 1623.

${ }^{59}$ Ibidem.
} 
Para Bonifácio de Andrada (PDS-MG), apenas "Os bons estrangeiros devem ter acolhida neste País (palmas), mas não os criminosos e agentes do exterior $^{\prime \prime 60}$. O mesmo parlamentar, no dia da votação da matéria, defende que o projeto é fundamental para que o governo brasileiro tenha "poderes bem extensos, prerrogativas bem eficientes para manter a ordem interna, no tocante aos estrangeiros considerados nocivos à situação nacional"61.

A grande imprensa entra no debate, criticando o texto ou o formato de seu envio e tramitação. É o caso do Estado de São Paulo, cujo editorial de 16 de julho 1980, "O Novo Estatuto do Velho Inimigo", repercute declarações do Ministro da Justiça:

Se o Ministro da Justiça admite, pelo menos como hipótese, que haja no projeto (leio palavras de S. Ex. ${ }^{-}$) "excessos a serem contidos, disposições inadequadas, omissões a suprir ou erros a corrigir", por que é que o Governo a que serve restringiu ao máximo seu período de tramitação no Congresso? E, se o Governo, pela boca do Subsecretário de Imprensa do Palácio do Planalto, Alexandre Garcia, recomenda a sua criatura, dizendo-a nascida de 8 anos de gestação e de consulta a toda legislação mundial sobre o assunto, por que haveria de furtar tal maravilha de acabamento à contemplação do Congresso, dando-lhe tão pouco tempo para admirá-la? (...) Estamos, na realidade, a assistir a um festival completo de mentira oficial e de hipocrisia governamental que contaminam o conteúdo do projeto e sua exposição de motivos, a formulação que lhe conferiu certa técnica legislativa especialista em facultar abusos de poder e a própria escolha de um regime de urgência para tramitação no Congresso Nacional ${ }^{62}$.

O Jornal do Brasil, em editorial de 09 de julho de 1980, intitulado "Por força de lei", critica o fato de o governo não ter aceito as emendas da oposição:

O Governo parece haver fechado a questão, fechando o texto. Pois o objetivo da nova lei é fechar. Fechar a fronteira aos imigrantes e, mais que isso, fechar o espírito fraterno com que o povo brasileiro recebe os estrangeiros, e com eles convive, a tal ponto que ao longo de nossa História se evidenciou aqui um processo de aculturação do alienígena, de cuja velocidade, amplitude e profundidade não há exemplo em outro qualquer país. (...) O nosso jeito de receber vai mudar: vamos renunciar, por força da lei, à nossa decantada arte da acolhida a que fez referência Sua Santidade. Não seremos o mesmo país ${ }^{63}$.

Para o Senador Paulo Brossard (PMDB-RS), que comenta os dois editoriais, aprovar a nova lei seria "trocar a identidade nacional", uma vez que o Brasil estaria correndo o risco de deixar de ser o país que recebe estrangeiros, como os seus próprios antepassados, assim como de tantos outros parlamentares. Ao afirmar

\footnotetext{
${ }^{60}$ Discurso de Bonifácio de Andrada (PSD-MG). DCN, 06/07/1980, p. 1725.

${ }^{61}$ Ibidem, p. 1730.

62 Transcrito em discurso do Senador Paulo Brossard (PMDB-RS), no DCN de 06/08/1980, p. 1748.

63 Ibidem.
} 
"eu também sou filho de imigrantes (...) eu também sou filho de estrangeiros", o parlamentar é apoiado por gritos de "Muito bem!" e palmas.

A Mesa do Senado, que é quem elabora as pautas do Congresso Nacional, marcou a votação do Projeto de Lei $n^{\circ}$ 9/80-CN para 5 de agosto de 1980, último dia do prazo. Para tornar a situação ainda mais tensa, a oposição denuncia o telegrama que o líder do PDS na Câmara dos Deputados, Nelson Marchezan (PDS-RS), teria enviado à bancada, isentando-a de estar presente no dia cinco, o que fatalmente não daria quórum para a votação, permitindo sua aprovação por decurso de prazo.

Depois de uma sessão extremamente tumultuada, com muito debate, aplausos, vaias e troca de acusações entre governistas e oposição, inicia-se a votação do Projeto de Lei $n^{\circ}$ 9/80-CN pela Câmara dos Deputados. A matéria recebe apenas cinco votos favoráveis - dos deputados Nelson Marchezan (PDS-RS), João Alberto (PDS-MA), Bonifácio de Andrada (PDS-MG), Adhemar de Barros Filho (PDS-SP) e Carlos Chiarelli (PDS-RS) - e 193 contrários. Como não se obteve quórum, sequer foi feita a votação no Senado e o projeto foi aprovado por decurso de prazo.

Passados pouco mais de três meses da sanção da Lei 8.615, é expulso do país o padre italiano Vito Miracapillo, que trabalhava na cidade de Ribeirão, Diocese de Palmares, em Pernambuco. Foi denunciado pelo Deputado Severino Cavalcanti, da bancada do PDS na Assembleia Legislativa de Pernambuco, por ter se recusado a celebrar, no 7 de setembro, missas em comemoração pelo dia da Independência. O religioso, argumentou, em carta, que não havia independência para um "povo reduzido a condição de pedinte e desamparado em seus direitos"64:

Quando fui expulso, no dia 30 de outubro, estava na sede da CNBB, em Brasília, porque toda a Igreja estava do meu lado. Um bispo me disse que todos os 204 bispos tinham votado para se solidarizar comigo, sem nenhum voto branco ou nulo, para que todos tomassem posição contra o governo. E no dia 30 saiu uma nota da CNBB dizendo que aquela data era dia de bem-aventurança, pelo que eu tinha vivido e testemunhado, mas, ao mesmo tempo de dor, porque acontecia a expulsão. Em Roma, todos os cardeais do Brasil foram convidados pela embaixada brasileira para um jantar, e logo que souberam que havia sido expulso, eles disseram que não podiam aceitar o convite, enquanto um padre católico estava sendo expulso do Brasil. Foi uma decisão muito forte que todos assumiram ${ }^{65}$.

Parlamentares de oposição viram no fato a primeira consequência da sanção do Estatuto dos Estrangeiros, confirmando suas piores expectativas.

\footnotetext{
${ }^{64}$ Ver Padre Vito Miracapillo conta detalhes sobre sua expulsão do Brasil, em: <http://www.a12.com/ noticias/detalhes/padre-vito-miracapillo-conta-detalhes-sobre-sua-expulsao-do-brasil > .

${ }^{65}$ Ibidem.
} 
Em agosto de 1981, o governo envia ao Congresso a Mensagem 325, de 1981, com propostas de alterações à Lei 6.815. Houve acordo com a oposição, solicitação de urgência, e aprovação em Plenário, no dia 10 de outubro. Enviada ao Senado Federal, a matéria também é aprovada e enviada à sanção no dia 21 de dezembro, transformando-se na Lei 6.964, de 09 de dezembro de 1981.

O apoiamento da oposição ao novo texto se deu em função de três principais alterações:

1) Introdução de inciso VIII no art. 13, incluindo os ministro de confissão religiosa ou membro de instituto de vida consagrada e de congregação ou ordem religiosa entre os estrangeiros com direito a visto temporário;

2) Incluindo no art. 46 (agora 47) a expressão "quando requisitados"66; e

3) Modificando o art. 74 (transformado em 75), para determinar que não se procederá à expulsão quando o estrangeiro tiver cônjuge brasileiro do qual não esteja divorciado ou separado, de fato ou de direito, e desde que o casamento tenha sido celebrado há mais de 5 (cinco) anos; ou filho brasileiro que, comprovadamente, esteja sob sua guarda e dele dependa economicamente.

Todos os demais artigos criticados pela oposição permaneceram inalterados, e estão em vigor até hoje.

Nos trinta e quatro anos que nos separam desta última alteração (além de outra mais recente, para modernizar o sistema eletrônico) ${ }^{67}$, tivemos duas tentativas governamentais de mudar a legislação migratória, uma enviada pelo presidente Fernando Henrique Cardoso e outra pelo presidente Luiz Inácio Lula da Silva ${ }^{68}$. Ambas ficaram engavetadas por anos. Enquanto o governo $\mathrm{FHC}$ retirou sua proposta, a do governo Lula (PL 5655/2009) acabou sendo apensada ao PL 2516/2015. O que nos chama atenção aqui é que, diferentemente da lei em vigor, estas duas novas propostas não foram objeto de polêmica nem de maiores interesses.

A pauta da criminalização da migração, no entanto, ganhou um novo e poderoso fôlego graças à complicada implementação da agenda antitráfico de pessoas no país, como já foi amplamente analisado ${ }^{69}$, afetando sobretudo os

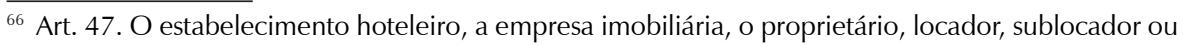
locatário de imóvel e o síndico de edifício remeterão ao Ministério da Justiça, quando requisitados, os dados de identificação do estrangeiro admitido na condição de hóspede, locatário, sublocatário ou morador.

${ }^{67}$ Lei $12.968 / 2014$.

${ }^{68}$ Consoante Exposição de Motivos que acompanha a matéria, assinada por Tarso Genro, Ministro da Justiça, "enquanto na lei em vigor o foco é a segurança nacional, na nova proposta a migração [é] tratada como um direito do homem (...) [e] a regularização migratória o caminho mais viável para a inserção do imigrante na sociedade".

${ }^{69}$ Ver "A temática do tráfico de pessoas no contexto brasileiro", de Marcia Sprandel e Guilherme Mansur (REMHU, revista Interdisciplinar da Mobilidade Humana, ano XVII, n. 35, jul-dez. 2010) e a tese de doutorado de Guilherme Mansur Dias, "Migração e Crime: desconstrução das políticas de segurança e tráfico de pessoas". Tese apresentada ao Instituto de Filosofia e Ciências Humanas, 
trabalhadores sexuais, com consequências ainda a serem avaliadas. Por outro lado, a Comissão de Juristas criada para elaborar anteprojeto de lei do Código Penal conclui seus trabalhos com a apresentação do PLS 236/2012, que cria um capítulo intitulado "Crimes Relativos a Estrangeiros", num evidente retrocesso ao que prevê o Código Penal em vigor ${ }^{70}$.

\section{Situação atual e reflexões para o debate}

Durante a tramitação do PLS 288/2013 no Senado (PL 2516, de 2015, na Câmara dos Deputados), emendas apresentadas pelo Senador Lasier Martins (PDT-RS), radialista e, portanto, formador de opinião, demonstram que os velhos fantasmas da defesa da segurança nacional e do estrangeiro ameaçador estão longe de ter sido superados. Em uma delas, Emenda no $5^{71}$, sugere a supressão da possibilidade de autorização de residência para estrangeiro que esteja em liberdade provisória ou em cumprimento de prisão cautelar ou de pena criminal, por entender que "isso pode abrir a porta para que indivíduos de conduta duvidosa venham a residir no nosso país". A aprovação de sua emenda supressiva criou um vácuo jurídico que precisará ser corrigido pelo relator na Câmara dos Deputados. Ou seja, foi a vitória (parcial) do preconceito sobre a juridicidade.

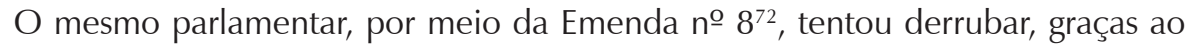
bom senso sem sucesso, o tratamento diferenciado dado aos povos indígenas pelo PLS 288, com o argumento de que "poder-se-ia conceber a possibilidade de territórios indígenas sobreporem-se às fronteiras nacionais, o que poderia implicar na temerária criação de áreas em que o livre transito de pessoas seria feito sem a fiscalização do governo nacional".

Ainda é cedo para avaliarmos que rumo tomará o parecer do relator, Deputado Orlando Silva, na Câmara dos Deputados. Em Audiências Públicas já realizadas, entidades da sociedade civil e representantes de imigrantes têm elogiado os avanços do novo texto e apontado resquícios da velha ideologia da segurança nacional, reivindicando alterações. Ainda não se ouviu o suficiente a visão dos parlamentares integrantes da Comissão Especial, mas um deles já rotulou como "fantasia romântica" da sociedade civil a defesa da mobilidade humana, uma vez que seriam precisos critérios rígidos de controle fronteiriço.

para obtenção do título de Doutor em Antropologia Social. Unicamp, março de 2014.

70 A Associação Brasileira de Antropologia, em nota, sugere a supressão deste capítulo, argumentando que o tratamento da questão migratória pelo PLS 236/2012 está contagiado pela tendência de criminalização dos movimentos migratórios e de punição criminal do migrante, além de criar injustificada distinção no tratamento a nacionais e estrangeiros e estar "impregnado de uma visão preconceituosa e xenófoba em relação ao estrangeiro. A nacionalidade não pode ser elemento de tipo penal" (ver "A questão dos estrangeiros no PLS 236/2012 (reforma do Código Penal) - um retrocesso". Brasília, 29/08/2012).

${ }^{71}$ Ver <http://www25.senado.leg.br/web/atividade/materias/-/materia/113700> .

${ }^{72}$ Ibidem. 
Em verbete sobre criminalização das migrações produzido para o Dicionário Crítico sobre Migrações Internacionais ${ }^{73}$, Mansur e Sprandel apontam que, embora a relação entre migração e crime seja coetânea à formação do Estado-nacional moderno e à codificação dos sistemas de justiça criminal a ele referidos, é a partir da década de 1980 que a criminalização das migrações passou a ganhar concretude e prioridade na agenda política de países hegemônicos, em função de uma estratégia política neoliberal que consiste em fazer da legislação penal, da narrativa criminal popular e da criminologia ferramentas de governança de questões sociais.

Para além do contexto atual brasileiro, no entanto, discutir legislações migratórias é, sim, discutir estado nacional, sua potencialidade como espaço da diferença vis-à-vis as configurações políticas anteriores e seus limites atuais para lidar com essa mesma diferença. Se, como bem lembra Giralda Seyferth, foi na virada do século 19 para o século 20 que se intensificou o debate sobre as "possíveis interferências de governos estrangeiros junto aos seus 'nacionais' em diáspora, além das (...) definições de migrantes preferenciais" ${ }^{\prime 7}$, nos parece que tal debate segue atual, embora com outras roupagens e referencias conceituais (como a agenda antitráfico, já mencionada).

Da mesma forma, embora a discussão sobre o interesse em imigrantes irregulares pela possibilidade de uma superexploração de sua mais-valia siga um fator importante de análise, não há como entender a morosidade na atualização da legislação migratória brasileira sem levar em consideração o debate sobre o estado-nacional e a democracia. Ou melhor, sobre os limites de uma democracia baseada em territorialidade. Enquanto isto não for questionado com profundidade, o ideal igualitário da democracia estará sendo constantemente desafiado:

Excluir da ordem política, mandar o imigrante embora, enquanto estrangeiro, do ponto de vista da nacionalidade, para fora do campo político (...), é uma forma para a ordem democrática de acertar com seu ideal igualitário: basta delimitar o campo político - delimitá-lo territorialmente ou com nacionalidade - e, correlativamente, constituir o código das inclusões no nacional e das exclusões do nacional, ou seja, os critérios pertinentes que discriminam aqueles que participam de direitos dos que (de direito) não participam da política (...) para que a ordem e a moral estejam sãs e salvas. Como ainda se tem a possibilidade de definir o território político (ou nacional) - e sabe-se que quanto a definição e a imposição de fronteiras constituem sempre lutas políticas ${ }^{75}$-, tal coisa permite conciliar o direito (i.e., a "paixão democrática" da igualdade) e o fato, ou seja, a discriminação, a segregação que se encontram assim fundadas, regulamentadas, legitimadas"76.

\footnotetext{
73 MANSUR, Guilherme, SPRANDEL, Marcia Anita. Criminalização das migrações. No prelo.

74 SEYFERTH, op. cit., p. 1.

75 Sobre a importância das fronteiras na formação do ethos nacional brasileiro ver Sprandel, Marcia. Breve genealogia sobre os estudos de fronteiras \& limites no Brasil. In OLIVEIRA, Roberto C. de, BAINES, Stephen (orgs). Nacionalidade e etnicidade em fronteiras. Brasília: UNB, 2005.

${ }^{76}$ SAYAD, op. cit., p. 276-277.
} 
Se somarmos às reflexões de Sayad (e à nossa história de leis e políticas migratórias) a mediocridade (no sentido de meio, de média, de mídia) que tem caracterizado os debates no Congresso $\mathrm{Naciona}^{77}$, podemos prever um período tenso para a aprovação de uma nova legislação migratória que consiga, ao menos, chamar a atenção dos parlamentares para a sua importância em termos de reconhecimento de direitos, sobretudo do direito à diferença, direito este que tem sido diariamente ameaçado em relação aos próprios nacionais ${ }^{78}$.

\section{Bibliografia}

BOURDIEU, Pierre. Um analista do Inconsciente. In SAYAD, Abdelmalek. A Imigração ou o Paradoxo da Alteridade. São Paulo: Editora da USP, 1999, p. 9-12.

CÂMARA DOS DEPUTADOS. Banco de Dados Discursos e Notas Taquigráficas. Disponível em: http://www2.camara.leg.br/deputados/discursos-e-notas-taquigraficas.

DIAS, Guilherme Mansur; SPRANDEL, Marcia Anita. A temática do tráfico de pessoas no contexto brasileiro. REMHU, Revista Interdisciplinar da Mobilidade Humana, ano XVII, n. 35, jul-dez. 2010, p. 50-77.

DIAS, Guilherme Mansur; SPARNDEL, Marcia Anita. Criminalização das migrações In Dicionário crítico sobre Migrações Internacionais. CAVALCANTI, Leonardo; TONHATI, T.; BOTEGA, Tuíla. Brasília: OBMIGRA, no prelo.

DIAS, Guilherme Mansur. Migração e Crime: desconstrução das políticas de segurança e tráfico de pessoas. Tese apresentada ao Instituto de Filosofia e Ciências Humanas, para obtenção do título de Doutor em Antropologia Social. Unicamp, março de 2014.

SAYAD, Abdelmalek. A Imigração ou o Paradoxo da Alteridade. São Paulo: Editora da USP, 1999.

SEYFERTH, Giralda. Imigrantes, estrangeiros: a trajetória de uma categoria incomoda no campo político. Trabalho apresentado na Mesa Redonda Imigrantes e Emigrantes: as transformações das relações do Estado Brasileiro com a Migração. 26a Reunião Brasileira de Antropologia, realizada entre os dias 01 e 04 de junho de 2008, Porto Seguro, Brasil. Disponível em: <http://www.abant.org.br/conteudo/ANAIS/CD_ Virtual_26_RBA/mesas_redondas/trabalhos/MR\%2012/giralda\%20seyferth.pdf >.

SIMMEL, Georg. O Estrangeiro. In MORAES FILHO, Evaristo de (org.). Georg Simmel: sociologia. São Paulo: Ática, 1983.

SPRANDEL, Marcia Anita. Breve genealogia sobre os estudos de fronteiras \& limites no Brasil. In OLIVEIRA, Roberto C. de; BAINES, Stephen (orgs.). Nacionalidade e etnicidade em fronteiras. Brasília: UNB, 2005.

\footnotetext{
${ }_{77}$ Ver os discursos parlamentares sobre "invasão haitiana" ou "invasão de médicos cubanos", por exemplo.

${ }^{78}$ Em função de inúmeras Propostas de Emenda à Constituição e Projetos de Lei atualmente tramitando nas duas Casas do Congresso Nacional que buscam restringir ao máximo os direitos de povos indígenas, populações quilombolas, populações tradicionais, população LGBT e religiões de matrizes africanas, entre outros grupos sociais. A recente instalação da CPI da Funai e do Incra, na Câmara dos Deputados, é mais um indicativo deste processo retrógrado capitaneado pelo Poder Legislativo.
} 


\section{Leis}

Decreto no 528, de 28 de junho de 1890. Regularisa o serviço da introducção e localisação de immigrantes na Republica dos Estados Unidos do Brazil. Disponível em: http://legis.senado.gov.br/legislacao/ListaNormas.action?numero=528\&tipo_ norma $=$ DEC\&data $=18900628 \&$ link $=\mathrm{s}$.

Decreto-Lei no 406, de 04 de maio de 1938. Dispõe sobre a entrada de estrangeiros no território nacional. Disponível em: https://www.planalto.gov.br/ccivil_03/ decreto-lei/1937-1946/Del0406impressao.htm.

Decreto-Lei no 7967, de 18 de setembro de 1945. Dispõe sobre a Imigração e a Colonização, e dá outras providências. Disponível em: http://www.planalto.gov.br/ ccivil_03/decreto-lei/1937-1946/Del7967.htm.

Lei no 2526, de 5 de julho de 1955. Isenta de visto consular turistas cidadãos de países Americanos. Disponível em: http://www2.camara.leg.br/legin/fed/lei/19501959/lei-2526-5-julho-1955-361044-publicacaooriginal-1-pl.html.

Lei no 4.473, de 12 de novembro de 1964. Dispõe sôbre atribuições das autoridades para fiscalizar a entrada de estrangeiros no território nacional, e dá outras providências. Disponível em: http://www.planalto.gov.br/ccivil_03/leis/19501969/L4473impressao.htm.

Decreto-Lei no 314, de 13 de março de 1967. Define os crimes contra a segurança nacional, a ordem política e social e dá outras providencias. Disponível em: http:// www.planalto.gov.br/ccivil_03/decreto-lei/1965-1988/Del0314.htm.

Decreto-Lei no 417, de 10 de janeiro de 1969. Dispõe sobre a expulsão de estrangeiros. Disponível em: http://www.planalto.gov.br/ccivil_03/decretolei/1965-1988/Del0417impressao.htm.

Ato Institucional no 13, de 5 de setembro de 1969. Institui a pena de banimento do Território Nacional para o brasileiro que se tornar inconveniente, nocivo ou perigoso à Segurança Nacional e dá outras providências. Disponível em: http:// www.planalto.gov.br/ccivil_03/AIT/ait-13-69.htm.

Ato Institucional no 14, de 5 de setembro de 1969. Dá nova redação ao parágrafo 11 do artigo 150 da Constituição do Brasil, acrescentando que não haverá pena de morte, de prisão perpétua, de banimento ou confisco, salvo nos casos de guerra externa, psicológica adversa, ou revolucionária ou subversiva nos termos que a lei determinar - esta disporá, também, sobre o perdimento de bens por danos causados ao erário ou no caso de enriquecimento ilícito no exercício de cargo, função ou emprego na administração pública direta ou indireta. Disponível em: http://www.planalto.gov.br/ccivil_03/AlT/ait-14-69.htm.

Decreto-Lei no 941, de 13 de outubro de 1969. Define a situação jurídica do estrangeiro no Brasil, e dá outras providências. Disponível em: http://www. planalto.gov.br/ccivil_03/decreto-lei/1965-1988/Del0941impressao.htm.

Lei $\mathbf{6 . 8 1 5}$, de 19 de agosto de $\mathbf{1 9 8 0}$. Define a situação jurídica do estrangeiro no Brasil, cria o Conselho Nacional de Imigração. Disponível em http://www.planalto. gov.br/Ccivil_03/Leis/L6815.htm. 


\section{Projetos de Lei}

Projeto de Lei no 5655, de 2009. Dispõe sobre o ingresso, permanência e saída de estrangeiros no território nacional, o instituto da naturalização, as medidas compulsórias, transforma o Conselho Nacional de Imigração em Conselho Nacional de Migração, define infrações e dá outras providências. Disponível em: http:// www.camara.gov.br/proposicoesWeb/fichadetramitacao?idProposicao $=443102$.

Projeto de Lei do Senado no 236, de 2012. Reforma do Código Penal. Disponível em: http://www25.senado.leg.br/web/atividade/materias/-/materia/106404.

PLS no 288, de 2013. Institui a Lei de Migração e regula entrada e estada de estrangeiros no Brasil.http://www25.senado.leg.br/web/atividade/materias/-/materia/113700.

Projeto de Lei no 2516, de 2015. Institui a Lei de Migração. Disponível em: http:// www2.camara.leg.br/proposicoesWeb/fichadetramitacao?idProposicao $=1594910$.

\section{Abstract}

\section{Migration and Crime: Law 6.815, 1980}

The article analyzes the debate and the circumstances of sending to the National Congress in1980, the Bill that was signed into Law 6.815,1980 (Alien Status). In the background of military dictatorship, in the full respect of cold war, the Condor Operation and the National Security Law, the text sent by General Jõao Figueiredo is intensely criticized by the opposition parliamentarians, intellectuals, trade unions and the mass media. In addition to presenting the main elements that guided the parliament debates and the most questioned aspects of the proposed Bill, the article analizes theorically the condition of the Foreigner as a threat, a legislative tradition dating back to the Empire, but that in the analyzed period, it has its own characteristics linked to the concepts of war and internal subversion. It aims to present information for policy makers and experts on the subject and allows the reader to reflect on the resilience on this speech (thirty-five years ago) in contemporary debates.

Keywords: Alien Status, anthropology of policy, National Congress, criminalization of migration, national security.

Recebido para publicação em 08/09/2015 Aceito para publicação em 05/11/2015 Received for publication in September, 08 ${ }^{\text {th }}, 2015$ Accepted for publication in November, 05 ${ }^{\text {th }}, 2015$ 


\section{ERRATA}

No artigo "Migração e crime: a Lei 6.815, de 1980", com número de DOI: 10.1590/1980-85852503880004508, publicado na Revista REMHU, Revista Interdisciplinar da Mobilidade Humana, vol. 23, número 45, na página 163.

Onde se lia:

Nos trinta e quatro anos que nos separam desta última alteração (além de outra mais recente, para modernizar o sistema eletrônico) ${ }^{67}$, tivemos duas tentativas governamentais de mudar a legislação migratória, uma enviada pelo presidente Fernando Henrique Cardoso e outra pelo presidente Luiz Inácio Lula da Silva ${ }^{68}$. Ambas ficaram engavetadas por anos. Enquanto o governo FHC retirou sua proposta, a do governo Lula (PL 5655/2009) acabou sendo apensada ao PL 2516/2015. O que nos chama atenção aqui é que, diferentemente da lei em vigor, estas duas novas propostas não foram objeto de polêmica nem de maiores interesses.

\section{Leia-se:}

Nos trinta e quatro anos que nos separam desta última alteração (além de outra mais recente, para modernizar o sistema eletrônico) ${ }^{67}$, tivemos duas tentativas governamentais de mudar a legislação migratória, uma enviada pelo presidente Fernando Collor (PL 1813, de 1991) e outra pelo presidente Luiz Inácio Lula da Silva (PL 5655/2009) ${ }^{68}$. Ambas ficaram engavetadas por anos. Enquanto o governo FHC retirou o PL1813, de 1991, o PL 5655, de 2009, acabou sendo apensada ao PL 2516/2015. O que nos chama atenção aqui é que, diferentemente da lei em vigor, estas duas novas propostas não foram objeto de polêmica nem de maiores interesses. 